\title{
SOCIAL CAPITAL AND COMMUNITY PARTICIPATION AMONG MIGRANT WORKERS IN CHINA
}

\author{
Neal A. Palmer and Douglas D. Perkins \\ Vanderbilt University \\ Qingwen Xu \\ Boston College
}

\begin{abstract}
In China, rapid development has prompted massive migration from rural to urban areas. Migrants' participation in Urban Residents Committees (URCs) and other community organizations offers opportunities for the development of social capital and democracy in contemporary China. We use 2006 survey data from a stratified convenience sample of 3,024 migrant workers in 7 Chinese cities to examine individual and community social capital and their relation to 3 types of community participation: (a) amount of contact with community organizations, (b) frequency of help sought from community organizations, and (c) the rate of participation in URC meetings. Multiple regressions yield, among 12 measures of individual and community-focused social capital, only neighborhood interaction and organizational social capital as consistently and significantly associated for all 3 types of participation. Other measures were associated with certain types of participation, or were nonsignificant. Implications for migration policy, community participation, and social capital in China are discussed. (C) 2010 Wiley Periodicals, Inc.
\end{abstract}

As globalization and centralization of power threaten local control, community participation remains an important means of individual and community influence and empowerment. Social capital is a multidisciplinary construct used for promoting formal and informal community participation (Perkins, Hughey, \& Speer, 2002),

\footnotetext{
We thank Dr. Xingping Guan, professor at Nankai University Department of Social Policy and Social Work and principal investigator of the China Ministry of Education's project "The Transition of China's Rural Labor to Urban Areas," for access to these data.

Correspondence to: Neal A. Palmer, Peabody \#90, 230 Appleton Place, Nashville, Tennessee 37203-5721.

E-mail: neal.a.palmer@gmail.com
} 
although, ironically, it has been examined most often in developed democracies in the West, where economic capital and social services are greater and human needs are fewer than in the developing world. Where social capital and community participation have been studied in less developed regions, results have been mixed (Campbell, Cornish, \& McLean, 2004; Mitchell \& Bossert, 2007), perhaps because of unfavorable political conditions and cultural differences, or because social capital indicators conceived in the West may not translate and apply directly to developing areas.

China offers a particularly interesting context for the study of participation and social capital due to its immense size, rapid development, deep history, and complex policies. China's opening markets and its cheap labor supply attracted foreign capital and enterprises, prompting a surge of migration from rural areas to urban areas in the early 1980s (Fan, 2001; Yang, 1999). These pull factors occurred as increasing surpluses of agricultural labor and growing income gaps between urban factory and farm workers further disincentivized remaining in rural areas (Fan, 2001). Since the central government's 1985 decision to lift strict regulations on population movement, economic migrants have been allowed and even encouraged to work and stay in China's growing towns and cities. Many of these migrant workers stay permanently, although a substantial proportion migrates from rural to urban areas for only part of the year ( $\mathrm{Li} \&$ Zahniser, 2002) and does so with fewer rights and privileges (Li et al., 2006).

The volume of China's internal migrants, which by some measures comprise $16.8 \%$ of its total population (National Bureau of Statistics of China, 2009), and the practice of chain migration (i.e., relying on social networks for migration) likely have profound effects on migrant workers' possession of social capital and their civic behaviors in cities. As social science research in China has generally failed to define social capital specific to its context (Bian's guanxi theory comes closest; Bian \& Ang, 1997), we apply Western-oriented social capital theory to Chinese migrant workers to examine the relationship between both individual-focused and community-focused social capital measures and three types of community participation.

Few studies, if any, have examined civic participation or social capital in the context of China's internal migration, and none has measured individual relative to community-focused social capital. Given the less consistent relationship between social capital and community participation in the developing world (Xu, Perkins, \& Chow, 2010), we adopted several measures of social capital to capture the contextually appropriate forms of social capital. It is our hypothesis that China's migrant workers with lower levels of individual and community-focused social capital are less likely to report participation than those with more social capital.

\section{Social Capital Theory and Community Participation}

Developed through the work of Bourdieu (1986), Coleman (1988), and Putnam (1993), social capital is a multidimensional construct that often includes cognitive (i.e., mutual trust) as well as structural (i.e., social networks) components. Participation in groups and networks can increase access to information channels and multiply one's social support resources, as well as diminish some of the disadvantages associated with a lack of human or financial capital. Research has increasingly given attention to context and ecological understandings of social capital, through such measures as trust in the community (Putnam, 1993), neighbor support (Perkins et al., 2002), community satisfaction, community place attachment (Perkins et al., 1996), sense of community, and life satisfaction (Prezza et al., 2001). 
Social capital theory assumes that building social networks, trust, and cohesion lead to active participation in local services and voluntary associations; individuals thereby identify and support collective goals that reinforce norms of reciprocity and a more connected and caring community. Social capital can also facilitate collective actions that encourage local political participation (Putnam, 1993). In contrast, where people feel isolated and alienated from social networks and wider society, they tend to withdraw from social and political participation (Henn, Weinstein, \& Forrest, 2005).

The connection between social capital and participation is not always so simple, however, and certainly depends on political context. While social capital facilitates social relationships and participation, the democratic institutional infrastructure is required to translate individual social capital into organized community political participation (e.g., Krishna, 2002). For example, Lindström (2005) observed higher rates of participation in Sweden compared with Arabic-speaking countries, and that social capital increased only some forms of participation.

\section{Social Capital, Migration, and Participation}

The relationship between social capital and participation among migrants is complex. Social capital has been found to increase the likelihood of international migration (Palloni et al., 2001), but the move may simultaneously result in a loss of social networks and disrupt civic participation, particularly if migrants view the move as temporary and have little stake or familiarity in the destination community. Compared with natives, immigrants are also less likely to be organizational members and, thus, have less social capital (Schlozman, Verba, \& Brady, 1995). Alternatively, migration could be accompanied by an increase in social capital. Obligations and cohesion among immigrants themselves are substantial due to shared experiences; although information channels may be reduced between migrants and formal power structures, immigrant organizations could at least partially make up for this potential deficit (Zhou, 2008).

Cheong et al. (2007) indicate that the role and importance of social capital may depend on migrants' social, economic, and political contexts. Motivations and incentives to increase social capital among immigrant populations may differ, and language, legal status, and cultural adjustments may determine the degree to which social capital is useful (Zhou, 2008). In addition, current operationalizations of the social capital concept may fail to measure types of social capital relevant to certain immigrant communities (Kao \& Rutherford, 2007). Therefore, research on social capital must be attuned to possible differences in social capital and how it operates in migrant populations.

Civic and political participation and their relation to social capital among migrants have not been widely studied. Despite numerous barriers, some migrants do participate, at times relatively extensively (Barreto \& Muñoz, 2003). In general, the role of social capital for civic and political participation is positive among migrants, as in the general population; however, this effect may vary by country of origin and destination as well as by formality of participation (Lindström, 2005; Togeby, 2004). Level of participation may also vary by period of immigration, with more recent immigrants being less active than earlier cohorts (Nakhaie, 2008). 


\section{Participation in China}

Participation in China must be understood contextually and as distinct from that envisioned in the West. For example, pre-reform (pre-1978) urban communities in China were work-unit-based and generally did not encompass the psychological, voluntary, and social meanings usually associated with geographic communities (Ruf, 1998). Community participation in the last three decades in urban China has been closely connected to the development of urban neighborhood communities and the transformation of Urban Residents Committees (URCs; Xu, 2007). The URC is a neighborhood-level, quasi-governmental organization present in all cities and towns across China. According to the PRC Urban Residents Committee Organizing Law (1989), these Committees, whose employees are civil servants, are autonomous, though they often work closely with and carry out the local government's administrative tasks (Derleth \& Koldyk, 2004), such as monitoring family-planning compliance and maintaining household registry rolls. They have also been used to translate government initiatives to the local context, such as implementing community programs like English and computer classes and organizing programs, celebrations, and events for children and the elderly (Xu, Gao, \& Yan, 2005).

Many city governments have made efforts, at least superficially, to incorporate migrant workers into urban communities and improve their wellbeing and public acceptance (e.g., holidays established to celebrate migrant workers; Xinhua News, 2007). However, migrant workers may lack the motivation to participate in rural villages that they might leave behind permanently, and in the urban communities where they work and live, marginalization both politically and socially creates barriers for migrant workers' participation (Huo, 2007; Wu \& Ye, 2008). A recent survey conducted in Wuhan (one of the biggest cities in central China) found that only about $11 \%$ migrant workers had participated in urban communities, and about $72 \%$ had not participated in their villages since they started to work in cities (Yang \& Zhu, 2007).

Barriers or factors that affect China's migrant workers' participation have been identified at both individual and policy/structural levels, including level of education, economic situation, awareness of participation, unequal access to services and education, and rural bias and discrimination (Huo, 2007; Yang \& Zhu, 2007; Zhao, 2008). In addition to these factors, $\mathrm{Wu}$ and Ye (2008) indicated that the lack of community participation can be attributed to the characteristics of migrant workers' social capital: migrant workers rely largely on social networks rooted in their villages; though these networks may provide close social bonds, and migrant workers do benefit from such networks (e.g., in employment and housing; Lee, 1998), they may provide few resources and opportunities for participation in either the rural or urban context; the latter suspicion prompts the current study.

\section{HYPOTHESES}

Despite the obstacles to participation listed above, some migrant workers do become more involved in their communities than others. In the research presented here, we aim to identify predictors of community participation for rural-to-urban migrant workers in China. We consider three levels of community participation: (a) amount of contact with community organizations, (b) frequency of help sought from community 
organizations, and (c) the rate of more formal participation in URC meetings. We hypothesize that for each dependent variable:

- Individual-focused social capital-family size and structure, number of relatives living in the city, and social support-will be positively associated with participation, after controlling for demographic variables.

- Community-focused cognitions and social capital-place attachment, trust in community, life and community satisfaction, organizational social capital, and neighboring —will be positively associated with participation, after controlling for demographic variables.

- Reflecting an ecological understanding of social capital, the addition of community-focused measures will contribute beyond the variation in participation explained by individual-focused measures.

\section{METHODS}

\section{Data Source}

Respondents for this study come from a survey of 3,024 people registered as rural residents who were working in seven cities across China in the fall of 2006 . The survey is part of the China Ministry of Education's project "The Transition of China's Rural Labor to Urban Areas" and was conducted according to research ethics and general practice in China.

Sampling involved four stages: (a) Seven cities, as primary destinations for migrant workers, across different geographic areas of China were first selected: five large cities-Guangzhou (south), Shanghai (east central), Shenyang (northeast), Tianjin (east), and Kunming (southwest), and two medium-sized cities-Yibin in Sichuan province and Weihai in Shandong province; due to budget constraints, target sample sizes were 500 for large cities and 250 for medium-sized cities; (b) using public information and labor statistics collected by city governments, specific administrative districts where the migrant workers were concentrated in each city were identified; two districts were then randomly selected; (c) industries were stratified according to their share of the local GDP, and two to three companies from a list of companies in each industry in the districts were randomly selected; when two to three companies were insufficient to recruit adequate participants to meet quotas, as was often the case for companies in service industries (e.g., restaurants), additional companies were added; and (d) migrant workers were randomly selected and recruited at each company, where they were interviewed face-to-face by trained graduate students.

Researchers of “The Transition of China's Rural Labor to Urban Area” project developed the survey questionnaire, which was pilot-tested and reviewed by experts to improve its validity and reliability. The questionnaire was administered in Chinese and collected demographic characteristics as well as information on employment and health, training and services, community activities, and perceptions toward the future. For purposes of this article, it was then translated to English by a bilingual researcher, and a native Chinese researcher checked the translations. The survey questionnaire contains 11 sections: demographics, employment and income, employment and job 
training, health and health care, housing, children's education, family situation, welfare program participation, service utilization, social activities and participation, and migration plan; additional findings from the project have been published by $\mathrm{Xu}$, Guan, and Yao (in press).

\section{Measures}

The dependent variables in this study are three varying measures of community participation, as obtained from the following survey questions: (a) How much contact do you have with residential area community organizations? (b) When you encounter difficulties, do you seek Urban Residents Committees and other community organizations for help? (c) Have you participated in community organizations' meetings, such as the General Assembly (of the Urban Residents Committee)? Each item was scored on a 4-point or 5-point Likert-type scale, where higher values indicate greater community participation. The items' intercorrelations ranged from .41 to .53, indicating that they were indeed related, but that they still measured different behavior. Thus, they were not combined here, allowing us to evaluate whether different social capital factors predict different levels of community involvement. Reported levels of participation were fairly low across all three dependent measures and declined as participation could be classified as more active, from contact with organizations to help seeking behaviors to participation in committee meetings.

The independent variables comprised demographic variables and measures of social capital. Demographic variables include age, gender, marital status, income, employment status, level of education and years of urban residence. Though increased urban experience could be of substantial use in locating opportunities for participation, it has been widely used in international immigration studies as a proxy to assess the level of incorporation and/or assimilation and is used in similar fashion here.

Given social capital's multidimensional nature, the following groups of social capital measures were included in the analysis:

Individual-focused social capital is defined in this study as persons' family structures and relationship networks. Chinese migrant workers carry much of their social capital through relationships established in their rural villages rather than through the formal political and social systems for organizational participation and behavior found elsewhere (e.g., Xu et al., 2010; Yip et al., 2007). Thus, this study assesses individual-focused social capital by focusing on migrant workers' personal informal relationship networks, using the following variables: presence of children under 12 years of age living in the house, presence of relatives over the age of 65 living in the house, family support (number of siblings living in the city), and friend social support (quantity of friends in the city: 5. a lot, 4. some, 3. not too many, 2. very few, 1. basically none). These measures are intended to capture effects of family structure and living arrangements as well as the utility of broader family and friend networks.

Community-focused social capital is constructed in a way to capture both cognitive and behavioral factors that have connected migrant workers with the neighborhood context in which they are living, and through which resources could be generated and accessed. Community-focused social capital is measured by place attachment (attachment to the city where migrant workers now live, a two-item scale generated from binary variables, KR-20 $\rho=.67$ ), community satisfaction (5. really like, 4. like, 3 . average, 2. don't like very much, 1. really don't like), life satisfaction (a two-item scale generated from Likert-type variables assessing overall satisfaction with life and 
confidence in one's future $(r=.43$, Cronbach's $\alpha=.60))$, perceived level of neighborhood interaction (4. a lot, 3. some, 2. very little, 1. almost none), organizational social capital (help received from community organizations in the past: 4 . often received, 3 . sometimes received, 2. rarely received, 1. never received), neighboring (received; i.e., experienced help from neighbors: 4. often, 3. sometimes, 2. rarely, 1. never), trust in people in the community (4. most people, 3. some people, 2. few people, 1. no one), and neighbor support (given four opportunities to respond, the number of friends listed from one's neighborhood rather than from work or from one's home village or province). The internal consistencies for the two scale measures, though not strong by psychometric standards for larger scales, are considered acceptable for very small scales (Schmitt, 1996).

These social capital-related items could not be combined into one scale because of inadequate internal consistency, and factor analyses suggested they were best left as separate constructs. The advantage of not combining them into a global scale is that it allows a comparison of measures in China to those used in other countries. Most were measured with Likert-type options or were count variables. Because they tended to be non-normally distributed, a series of dummy variables was initially created for these items, and models specified according to tests of fit; this more technical method did not produce results substantially different from those obtained by simply treating variables as continuous, however. Thus, the simpler models are presented here.

\section{Sample}

Table 1 presents the mean, standard deviation, and sample sizes of the dependent and independent variables. The average age was 31 years. Sixty percent of the respondents were male, and just over half (54\%) were married. A majority $(52 \%)$ had completed junior high school, though $22 \%$ had finished only elementary school or less; $26 \%$ completed senior high school or beyond. Respondents reported a mean income of 1,058 yuan per month (median 900 ), or about $\$ 155$, and they had an average of about 5 years of urban residence. More than $17 \%$ had children. They also noted relatively extensive social support, with more than half having one or more siblings residing in the same city, and nearly half reporting substantial friend support ("some" or "a lot" of friends) in the city. For community-focused measures, migrant workers' responses revealed an interesting pattern: they reported more trust and neighborhood social interaction, but less neighbor support and organizational social capital. Although nearly half of respondents reported at least a moderate level of neighboring ("often" or "sometimes" able to get help from neighbors), few reported a high proportion of support from neighbors, indicating that family and friends from the village or work were a more common source of support.

\section{Statistical Methods}

During the data cleaning and preparation stages, a significant amount of missing data, resulting primarily from nonresponse on two of the social capital measures (organizational social capital and life satisfaction) and the third dependent variable (participation in URC meetings), became a concern. Comparison tests showed that the mean scores between the complete and sample (based on listwise deletion) datasets were significantly different for only 5 of the 23 variables, and even then, mean scores were not substantively different. Data were thus imputed using chained equations ( $m=20$, within the range suggested by Royston, 2004); thus all 3,024 participants were 
Table 1. Descriptive Statistics $(N=3,024)$

\begin{tabular}{|c|c|c|c|c|}
\hline Variable & Mean & $S D$ & Min. & Max. \\
\hline \multicolumn{5}{|l|}{ Dependent variable } \\
\hline \multicolumn{5}{|l|}{ DV1: Contact with community organizations } \\
\hline Regular/some (prop.) & 0.25 & & & \\
\hline Very little/none (prop.) & 0.75 & & & \\
\hline DV2: Frequency of help sought from community orgs & 1.28 & $(0.62)$ & 1 & 4 \\
\hline Frequent (prop.) & 0.01 & & & \\
\hline Some (prop.) & 0.07 & & & \\
\hline Fair (prop.) & 0.12 & & & \\
\hline Never (prop.) & 0.80 & & & \\
\hline \multicolumn{5}{|l|}{ DV3: Rate of participation in URC meetings } \\
\hline Often/some (prop.) & 0.06 & & & \\
\hline Little/never (prop.) & 0.94 & & & \\
\hline \multicolumn{5}{|l|}{ Independent variables } \\
\hline Married/cohabitating (prop.) ${ }^{\mathrm{a}}$ & 0.54 & & & \\
\hline Male (prop. $)^{\mathrm{b}}$ & 0.60 & & & \\
\hline Elementary school or less $(<6 \text { years, prop. })^{c}$ & 0.22 & & & \\
\hline Senior high school or more $(9+\text { years; prop. })^{c}$ & 0.26 & & & \\
\hline Age & 30.72 & $(10.71)$ & 15 & 66 \\
\hline Years of urban residence & 5.25 & $(5.26)$ & 0.02 & 41.67 \\
\hline Monthly income (per 100 yuan) & 10.58 & $(7.61)$ & 0 & 105 \\
\hline 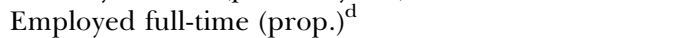 & 0.83 & & & \\
\hline \multicolumn{5}{|l|}{ Individual-focused social capital measures } \\
\hline Elderly relatives in home & 0.16 & $(0.49)$ & 0 & 4 \\
\hline One or more children under age 12 in home (prop. $)^{\mathrm{e}}$ & 0.17 & & & \\
\hline Family support & 1.12 & (1.39) & 0 & 7 \\
\hline Friend support & 3.40 & $(1.02)$ & 1 & 5 \\
\hline \multicolumn{5}{|l|}{ Community-focused social capital measures } \\
\hline Place attachment & 0.88 & $(0.85)$ & 0 & 2 \\
\hline Community satisfaction & 3.34 & $(0.96)$ & 1 & 5 \\
\hline Life satisfaction & 7.52 & (1.53) & 2 & 10 \\
\hline Neighborhood social interaction & 2.23 & $(1.00)$ & 1 & 4 \\
\hline Organizational social capital & 1.48 & $(0.80)$ & 1 & 4 \\
\hline Neighboring & 2.21 & $(1.06)$ & 1 & 4 \\
\hline Trust & 2.98 & $(0.90)$ & 1 & 4 \\
\hline Neighbor support & 0.32 & $(0.70)$ & 0 & 4 \\
\hline
\end{tabular}

Note. $\mathrm{SD}=$ standard deviation; $\mathrm{URC}=$ urban residents committee.

${ }^{\mathrm{a}}$ Unmarried.

${ }^{\mathrm{b}}$ Female.

'Junior high school completion (6-9 years).

${ }^{\mathrm{d}}$ Non-full-time employment.

${ }^{\mathrm{e}}$ No children under age 12 in the home.

included in the analysis. Later analysis results obtained from the imputed and original datasets reveal few substantial differences.

Logistic and ordinal logistic regressions with robust standard errors, using Stata 11 software, are used to examine the relationship between social capital and participation. Initially, ordinal logistic regressions were used for all three dependent variables, but because the parallel slopes assumption was violated for dependent variables 1 and 3, they were transformed into binary variables and subsequently analyzed using logistic regression. For each dependent variable, demographic variables are included in model 1, followed by two additional steps: individual/family measures of social capital, and community measures. 


\section{RESULTS}

Results of hierarchical logistic and ordinal logistic regressions, reported in Tables 2, 3 and 4, indicate that two social capital measures-neighborhood social interaction and organizational social capital-as well as education, were significantly predictive of all three types of community participation. Completion of senior high school or more, as compared with completion of only junior high school, increased the odds of the three levels of participation by $1.39,1.41$, and 2.35, respectively. One-unit increases in neighborhood social interaction increased the odds of participation by $1.69,1.35$, and 1.37, while one-unit increases in organizational social capital increased the odds of participation by $2.75,4.51$, and 2.35 .

Other individual-focused measures of social capital were differentially associated with the various types of participation. The presence of young children in the home was strongly positively associated with contact with community organizations, while the presence of elderly kin in the home was strongly positively associated with participation in URC meetings.

Several community-focused measures were also differentially associated with participation. Life satisfaction was positively associated with contact with community

Table 2. Logistic Regression of Independent Variables on Contact With Community Organizations (DV1)

Model 1 B Model 2 B Model 3 B (SE) Odds ratio

Independent variables

Married/cohabitating (prop.) ${ }^{\mathrm{a}}$

Male (prop.) ${ }^{\mathrm{b}}$

Elementary school or less $(<6 \text { years })^{c}$

Senior high school or more $(9+\text { years })^{c}$

Age

Years of urban residence

Monthly income (per 100 yuan)

Employed full-time ${ }^{\mathrm{d}}$

Individual-focused social capital measures

Elderly relatives in home

One or more children under age 12 in home ${ }^{\mathrm{e}}$

Family support

Friend support

Community-focused social capital measures

Place attachment

Community satisfaction

Life satisfaction

Neighborhood social interaction

Organizational social capital

Neighboring

Trust

Neighbor support

Constant

$R^{2}$

\begin{tabular}{|c|c|c|c|c|}
\hline 0.116 & -0.158 & -0.188 & $(0.155)$ & 0.829 \\
\hline$-0.152^{+}$ & $-0.160^{+}$ & 0.000 & $(0.108)$ & 1.000 \\
\hline$-0.470^{* * *}$ & $-0.488^{* * *}$ & $-0.446^{* * *}$ & $(0.148)$ & 0.640 \\
\hline $0.632^{* * *}$ & $0.630 * * *$ & $0.331^{* * *}$ & $(0.116)$ & 1.392 \\
\hline-0.003 & 0.009 & 0.012 & $(0.008)$ & 1.012 \\
\hline $0.033^{* * *}$ & $0.022^{*}$ & $0.019^{+}$ & $(0.011)$ & 1.019 \\
\hline $0.011^{*}$ & 0.007 & $0.013^{*}$ & $(0.006)$ & 1.013 \\
\hline \multirow[t]{13}{*}{$0.266^{*}$} & $0.219^{+}$ & 0.160 & $(0.150)$ & 1.174 \\
\hline & 0.001 & -0.152 & $(0.110)$ & 0.859 \\
\hline & $0.611^{* * *}$ & $0.505^{* * *}$ & $(0.148)$ & 1.657 \\
\hline & 0.000 & 0.018 & $(0.036)$ & 1.018 \\
\hline & $0.229 * * *$ & 0.013 & $(0.055)$ & 1.013 \\
\hline & & -0.010 & $(0.065)$ & 0.990 \\
\hline & & $-0.108^{+}$ & $(0.061)$ & 0.898 \\
\hline & & $0.121^{* *}$ & $(0.038)$ & 1.129 \\
\hline & & $0.527^{* * *}$ & $(0.056)$ & 1.694 \\
\hline & & $1.011^{* * *}$ & $(0.071)$ & 2.748 \\
\hline & & $0.126^{*}$ & $(0.052)$ & 1.134 \\
\hline & & 0.091 & $(0.065)$ & 1.095 \\
\hline & & $0.149^{*}$ & $(0.068)$ & 1.161 \\
\hline$-1.606^{* * *}$ & $-2.587^{* * *}$ & $-5.952^{* * *}$ & $(0.452)$ & \\
\hline 0.034 & 0.049 & 0.220 & & \\
\hline
\end{tabular}

Note. $\mathrm{SE}=$ standard error.

${ }^{\mathrm{a}}$ Unmarried.

${ }^{\mathrm{b}}$ Female.

Junior high school completion (6-9 years).

${ }^{\mathrm{d}}$ Non-full-time employment.

${ }^{\mathrm{e}}$ No children under age 12 in the home.

${ }^{*} p<.05 ;{ }^{* *} p<.01 ;{ }^{* * *} p<.001 ;{ }^{+} p<.10$. 
Table 3. Ordinal Logistic Regression of Independent Variables on Help-Seeking From Community Organizations (DV2)

Model 1 B Model 2 B Model 3 B $\quad$ (SE) Odds ratio

\begin{tabular}{|c|c|c|c|c|c|}
\hline \multicolumn{6}{|l|}{ Independent variables } \\
\hline Married/cohabitating (prop.) ${ }^{\mathrm{a}}$ & 0.090 & -0.031 & -0.046 & $(0.170)$ & 0.955 \\
\hline Male (prop. $)^{\mathrm{b}}$ & -0.099 & -0.114 & 0.115 & $(0.119)$ & 1.122 \\
\hline Elementary school or less $(<6 \text { years })^{c}$ & -0.158 & -0.160 & 0.003 & $(0.160)$ & 1.003 \\
\hline Senior high school or more $(9+\text { years })^{c}$ & $0.685^{* * *}$ & $0.675^{* * *}$ & $0.350^{* *}$ & $(0.127)$ & 1.419 \\
\hline Age & -0.001 & 0.007 & 0.012 & $(0.008)$ & 1.012 \\
\hline Years of urban residence & 0.009 & 0.000 & -0.005 & $(0.013)$ & 0.995 \\
\hline Monthly income (per 100 yuan) & $0.009^{+}$ & 0.007 & $0.016^{* *}$ & $(0.006)$ & 1.016 \\
\hline Employed full-time ${ }^{\mathrm{d}}$ & 0.102 & 0.072 & -0.028 & $(0.171)$ & 0.972 \\
\hline \multicolumn{6}{|l|}{ Individual-focused social capital measures } \\
\hline Elderly relatives in home & & 0.057 & -0.078 & $(0.127)$ & 0.925 \\
\hline One or more children under age 12 in home $\mathrm{e}^{\mathrm{e}}$ & & $0.293^{*}$ & 0.168 & $(0.163)$ & 1.183 \\
\hline Family support & & -0.018 & 0.009 & $(0.041)$ & 1.009 \\
\hline Friend support & & $0.199^{* * *}$ & -0.011 & $(0.060)$ & 0.989 \\
\hline \multicolumn{6}{|l|}{ Community-focused social capital measures } \\
\hline Place attachment & & & 0.028 & $(0.071)$ & 1.028 \\
\hline Community satisfaction & & & 0.034 & $(0.071)$ & 1.035 \\
\hline Life satisfaction & & & 0.041 & $(0.043)$ & 1.042 \\
\hline Neighborhood social interaction & & & $0.297^{* * *}$ & $(0.063)$ & 1.346 \\
\hline Organizational social capital & & & $1.506^{* * *}$ & $(0.076)$ & 4.509 \\
\hline Neighboring & & & $0.187^{* *}$ & $(0.061)$ & 1.206 \\
\hline Trust & & & -0.049 & $(0.073)$ & 0.952 \\
\hline Neighbor support & & & 0.042 & $(0.076)$ & 1.043 \\
\hline Cut 1 Constant & $1.771^{* * *}$ & $2.570^{* * *}$ & 6.069 & 0.486 & \\
\hline Cut 2 Constant & $2.898^{* * *}$ & $3.703^{* * *}$ & 7.643 & 0.495 & \\
\hline Cut 3 Constant & $5.209^{* * *}$ & $6.020^{* * *}$ & 10.410 & 0.541 & \\
\hline$R^{2}$ & 0.015 & 0.022 & 0.236 & & \\
\hline
\end{tabular}

Note. $\mathrm{SE}=$ standard error.

${ }^{\text {a Unmarried. }}$

${ }^{\mathrm{b}}$ Female.

Junior high school completion (6-9 years).

${ }^{\mathrm{d}}$ Non-full-time employment.

eNo children under age 12 in the home.

${ }^{*} p<.05 ;{ }^{* *} p<.01 ;{ }^{* * *} p<.001 ;{ }^{+} p<.10$.

organizations but not with other dependent variables. Neighboring was positively associated with both contact with and help seeking from community organizations, and neighbor support was positively associated with contact with community organizations. Trust in community members, place attachment, and life satisfaction were largely unassociated with participation.

Finally, support for the overall fit of the models is found in the $R^{2}$ reported in Tables 2, 3 and 4; model 3 predicts $22 \%, 24 \%$, and $17 \%$ of the variance for the three dependent variables, respectively. As a set, community-focused measures of social capital substantially improved the variance explained for each outcome, supporting hypothesis 3 .

\section{DISCUSSION}

The different social capital indicators used in this study permit an extended comparison of the impact on participation of different sources of social capital. The 
Table 4. Logistic Regression of Independent Variables on Participation in URC Meetings (DV3)

Model 1 B Model 2 B Model 3 B $\quad$ (SE) Odds ratio

\begin{tabular}{|c|c|c|c|c|c|}
\hline \multicolumn{6}{|l|}{ Independent variables } \\
\hline Married/cohabitating (prop.) ${ }^{\mathrm{a}}$ & 0.167 & 0.076 & 0.013 & $(0.316)$ & 1.013 \\
\hline Male (prop.) ${ }^{\mathrm{b}}$ & -0.036 & -0.058 & 0.123 & $(0.203)$ & 1.131 \\
\hline Elementary school or less $(<6 \text { years })^{c}$ & -0.204 & -0.222 & -0.071 & $(0.280)$ & 0.931 \\
\hline Senior high school or more $(9+\text { years })^{c}$ & $1.081^{* * *}$ & $1.060^{* * *}$ & $0.854^{* * *}$ & $(0.196)$ & 2.349 \\
\hline Age & -0.021 & -0.014 & -0.017 & $(0.017)$ & 0.983 \\
\hline Years of urban residence & 0.005 & -0.004 & -0.001 & $(0.023)$ & 0.999 \\
\hline Monthly income (per 100 yuan) & 0.008 & 0.007 & 0.009 & $(0.010)$ & 1.009 \\
\hline Employed full-time $^{\mathrm{d}}$ & -0.178 & -0.168 & -0.266 & $(0.265)$ & 0.766 \\
\hline \multicolumn{6}{|l|}{ Individual-focused social capital measures } \\
\hline Elderly relatives in home & & $0.566^{* * *}$ & $0.509^{* * *}$ & $(0.143)$ & 1.664 \\
\hline One or more children under age 12 in home $\mathrm{e}^{\mathrm{e}}$ & & 0.075 & -0.064 & $(0.294)$ & 0.938 \\
\hline Family support & & -0.022 & -0.002 & $(0.070)$ & 0.998 \\
\hline Friend support & & $0.225^{* *}$ & 0.028 & $(0.100)$ & 1.028 \\
\hline \multicolumn{6}{|l|}{ Community-focused social capital measures } \\
\hline Place attachment & & & -0.081 & $(0.114)$ & 0.922 \\
\hline Community satisfaction & & & 0.109 & $(0.125)$ & 1.115 \\
\hline Life satisfaction & & & 0.103 & $(0.069)$ & 1.108 \\
\hline Neighborhood social interaction & & & $0.316^{* *}$ & $(0.118)$ & 1.372 \\
\hline Organizational social capital & & & $0.853^{* * *}$ & $(0.104)$ & 2.347 \\
\hline Neighboring & & & 0.095 & $(0.102)$ & 1.100 \\
\hline Trust & & & 0.049 & $(0.128)$ & 1.050 \\
\hline Neighbor support & & & 0.139 & $(0.115)$ & 1.149 \\
\hline Constant & $-2.484^{* * *}$ & $-3.471^{* * *}$ & $-6.549^{* * *}$ & $(0.885)$ & \\
\hline$R^{2}$ & 0.040 & 0.056 & 0.167 & & \\
\hline
\end{tabular}

Note. $\mathrm{URC}=$ urban residents committee; $\mathrm{SE}=$ standard error.

${ }^{\mathrm{a}}$ Unmarried.

${ }^{\mathrm{b}}$ Female.

'Junior high school completion (6-9 years).

${ }^{\mathrm{d}}$ Non-full-time employment.

${ }^{\mathrm{e}}$ No children under age 12 in the home.

${ }^{*} p<.05 ;{ }^{* *} p<.01 ;{ }^{* * *} p<.001 ;{ }^{+} p<.10$.

literature on migrant community participation is relatively sparse, and this represents the first quantitative study of community participation by migrant workers in China. As most past research on community participation by any group has been done in Western countries, especially the United States, that will be the context for comparison in this discussion unless otherwise noted.

In this study, education, neighborhood social interaction, and organizational social capital were predictive of all three types of community participation. Consistent with previous research, education is positively related to community participation; predominately low levels of education among rural-to-urban migrant workers may limit their understanding and awareness of community participation and affect their capacity to build useful social capital as well. As expected, higher levels of neighborhood social interaction and prior positive experiences with organizations also predict all three types of community participation. Contact with and frequency of help sought from community organizations understandably increases with prior success and evidence of the benefits of involvement. The positive effect of neighbor interaction suggests that neighborhoods with more social activity provide more opportunities to become involved and limit migrants' ability to remain anonymous and isolated. 
Rural-to-urban migrant workers, like their peers in China's rural areas, have strong "bonding" social capital instead of "bridging" social capital (Xu et al., 2010); thus, the social capital they possess helps connect migrant workers together as a group, but not necessarily to urban mainstream communities. The relatively small number of migrant workers with prior success with organizations in urban cities is expected, given the unfamiliarity, distrust, and distance that migrant workers might have about urban community organizations because of the long-term urban-rural distinction; migrant workers may turn to the community for help only when they cannot obtain what they need through their rural-based family or friend networks or from other migrant workers.

Nevertheless, the relationship between participation and some types of community-focused social capital is encouraging. Although China has a relatively limited history of encouraging civic participation, especially in the past 60 years, and may not yet have harnessed the potential advantages of structural social capital, this form of social capital, that is, social capital based on formal membership and connection with community organizations, is likely to become more important as the country becomes more open and perhaps less centralized and more democratic (Liu \& Liu, 2008).

In this study, family and friend supports were included as individual-focused social capital. However, departing from generally understood connections between social capital and participation in western societies, family support was not associated with community participation in this study, and friend support demonstrated a significant association in model 3 only for contact with community organizations. It is noted that migrant workers in China do have support networks (e.g., Lee, 1998; Yip et al., 2007); many migrant workers locate jobs through friend networks, and they rely on loans from friends and relatives rather than through more formal channels when unexpected or large financial costs arise in the city. Such networks have not apparently translated into broader forms of participation. The different outcomes for friend/ family support and neighbor support in different contexts have also been found for high school adolescents in the United States (Seidman, Allen, Aber, \& Mitchell, 1995).

Similar to previous studies (Perkins et al., 1996), informal neighboring was associated with participation in formally organized groups, specifically contact with and help-seeking from community organizations. Migrant workers may locate opportunities for organizational participation through interactions with neighbors, but interestingly, not use such interactions as bases for URC meeting participation. Migrant workers may fail to see the utility of neighborhood relations if these are likely to be abandoned with their next move, rather than believe simply that URCs themselves are ineffective at addressing their substantial needs. The present findings suggest that, in China, social capital among migrant workers may not be cumulative; instead, people may tend to rely on one source of support or another, depending on the goal in question and the perceived utility of traditional networks.

We note that number of children and number of elderly kin living in the household were differentially associated with certain types of participation. Migrant workers may participate more readily in urban communities and community organizations if doing so might help meet their needs in care and improve the quality of life for their families. People moving from rural villages to urban communities leave behind their rural village-based family and friend support networks and develop new ones in the urban setting. As their children and parents are apt to spend more time in the more immediate neighborhood than they are, migrant workers' needs for care and their interests in their children and the elders' well-being cannot easily be met by their 
rural, village-based family members and friends. Thus, the positive association between the presence of young children in the home and contact with community organizations may reflect a positive role that organizations can play in the lives of urban migrant workers. Similarly, the positive association between the presence of elderly kin in the home and participation in URC meetings may reflect the common responsibility of URCs for planning social activities, service programs and community events (Xu, Gao, \& Yan, 2005). Participation, as analyzed in this study, is thus shown to be need-based and perhaps sporadic in nature.

The generally non-significant coefficients for other measures of social capital, such as place attachment, trust in community members, and community satisfaction, are also supported by the mixed results and ambiguity of prior research. For instance, though Yip et al. (2007) found trust to be predictive of health in rural China, Wang, Schlesinger, Wang, and Hsiao (2009) have found the opposite to be true. Such ambiguity suggests that the relationship between some types of social capital and community participation does not operate for rural-to-urban migrant workers in China, or that those types of social capital are either inapplicable to that population or possibly not adequately measured. In addition, though some social capital indicators failed to be predictive, the set of community-focused measures as a whole, including neighborhood social interaction and organizational social capital, added significantly to the prediction of each type of community participation beyond the demographic and more individual-focused concepts.

\section{Study Limitations and Strengths}

In most—probably all-countries, the majority of citizens do not actively participate in neighborhood improvement organizations (Dekker \& Van Kempen, 2008). China has less history of formal civic participation than does the West, and migrant workers, particularly those without legal (authorized) residency, may be particularly unlikely to participate. It is, thus, unsurprising that our data were relatively skewed toward little participation, particularly for the third dependent variable-formal participation in URCs. The models therefore predict relatively exceptional behavior for the migrant population. This lower amount of participation in organizations and URCs is not unexpected for migrant workers. Migrant workers lack the advantages that come with full urban residence permits and may, therefore, remain excluded from the advantages such participation would confer.

The generalizability of the relationships observed here is unknown. The sample should not be considered nationally representative, even though a stratified sampling process was used in seven cities from different regions of China and from more than 30 different sites. In this nonrandom convenience sample located through businesses, the utility of social capital may have been affected by factors associated with the businesses chosen. Intentions in seeking out organizational support may have varied by business, for instance. Relatively few respondents reported participating in community organizations, which may reflect hesitancy to claim a more active urban citizenship. Nonetheless, the migrant population has been the subject of considerable interest to the government and of prior research in China, due to the social tensions inherent in and created by such a process; in this sense, perceived pressure to bias responses may not be as substantial as could normally be expected with this typically marginalized population.

In addition, the study is cross-sectional, which prevents causal explanations of the relationships between participation and forms of capital observed here. For example, instead of neighborhood social interaction and organizational social capital encouraging 
migrants to participate more in their new communities, participation itself may enhance new residents' willingness to interact with their neighbors and their perception of organizational social capital.

Further, although the survey measures and wordings have face validity and have largely been validated in previous research, items measuring social capital failed to hold together in a single scale, raising doubts about the construct validity of the measures, at least with this sample of Chinese migrant workers. Finally, most of these measures are based on perceptions of neighborhood qualities; more objective measures might produce different results (Perkins et al., 1996; Ziersch, Baum, MacDougall, \& Putland, 2005).

The greatest strength of this study is likely the rare opportunity to assess different indicators of social capital, support, and community participation and help-seeking and their relationships in an important but difficult to reach population in the world's most populous country, and to compare it with both general and migrant populations in other parts of the world. In China, many millions of migrant workers who may be most in need of assistance lack the proximal informal support systems most residents use and take for granted. They, thus, stand to benefit the most from community participation (Xu \& Chow, 2006) and insights provided here.

\section{CONGLUSIONS}

The volume of internal migrant workers in China speaks to widespread aspirations of a better life for migrant workers and their families. Migrant workers' social capitallocated in individual-focused as well as community-focused components-is clearly related to their participation, supporting hypotheses 1, 2, and 3. Logically, prior success with organizations tends to lead to greater participation, as does neighborhood social interaction. Considering this in light of the positive effects of family-centered variables such as elderly kin and young children in the household, the relationship between social capital and participation for Chinese migrant workers may depend on more physically tangible evidence and reasons, rather than on more psychological concepts like trust.

This article presents compelling arguments for reexamining the conceptualizations and operationalizations of social capital with respect to social context. Providing some support for our hypotheses, some measures of individual-focused and community-focused social capital were positively associated with participation, though some measures, such as those based on friend and family support networks, were nonsignificantly associated. What can first be seen as inconclusive results regarding the effects of social capital on community participation can be reinterpreted through the complex Chinese social lens. In a country with a short and limited history of civic participation, traditional Western expectations of participation and understanding of social capital may prove incomplete or inaccurate. The Chinese migrant workers studied here demonstrated concrete reasons for participating in community organizations; more cognitive-based notion of social capital, such as trust, place attachment, and community satisfaction, did not apparently factor into the decision to participate, challenging the cognitive attachments to community understood to be valuable in the West. Together with the general nonsignificance for social support, these findings demonstrate that the difficult realities of migrant life strain the 
helpfulness of support networks and the potential to develop connections to their neighborhoods.

Findings in this study also argue for greater social support structures offered by the government. China's central government is increasingly aware of the massive scale of internal migration within the country, as it has been the source of profound social changes and tensions across society. The lives of migrant workers feature difficulties beyond the typical growing pains associated with the burgeoning Chinese economy. Though community participation theoretically offers a way to improve migrant workers' lives, some difficulties may be overcome only with great effort, regardless of social capital, if larger structural barriers in China, i.e., the urban-rural distinction and its associated discriminatory opportunity structure for migrant workers, are also present (Huo, 2007; Yang \& Zhu, 2007; Zhao, 2008). Beyond social capital, what it means to "participate" may be different in China than in the West. Persons in China, with a more recent history of state-sponsored social support, may be less accustomed to relying on the community for support. As the country develops, and this state support structure further deteriorates, one would expect community participation to increase.

Finally, and most speculatively, community participation may offer a way to become more involved in basic democratic organizations in China. Urban Residents Committees provide a voice, particularly for permanent residents, in the political process, and this early form of democratization may transform the country in the future. Though URCs remain less accessible for migrant workers, some nonetheless choose to become involved. Migration typically represents not so much a means to accumulate financial resources for selfish reasons, but rather a means of survival in a time of great social and economic upheaval in China. Community participation, in turn, represents an extension of these priorities. As residency policies continue to ease, participation in all types of community organizations may offer Chinese migrant workers a way to pursue increased rights and services.

\section{REFERENGES}

Barreto, M., \& Muñoz, J.A. (2003). Reexamining the "politics of in-between": Political participation among Mexican immigrants in the United States. Hispanic Journal of Behavioral Sciences, 25(4), 427-447.

Bian, Y., \& Ang, S. (1997). Guanxi networks and job mobility in China and Singapore. Social Forces, 75(3), 981-1005.

Bourdieu, P. (1986). The forms of capital. In J. Richardson (Ed.), Handbook of theory and research for the sociology of education (pp. 241-258). New York: Greenwood.

Campbell, C., Cornish, F., \& McLean, C. (2004). Social capital, participation and the perpetuation of health inequalities: Obstacles to African-Caribbean participation in "partnerships" to improve mental health. Ethnicity and Health, 9(4), 313-335.

Cheong, P.H., Edwards, R., Goulbourne, H., \& Solomos, J. (2007). Immigration, social cohesion, and social capital: A critical review. Critical Social Policy, 27(1), 24-49.

Coleman, J. (1988). Social capital in the creation of human capital. American Journal of Sociology, 94, S95-S120.

Dekker, K., \& Van Kempen, R. (2008). Places and participation: Comparing resident participation in post-WWII neighborhoods in Northwest, Central and Southern Europe. Journal of Urban Affairs, 30(1), 63-86. 
Derleth, J., \& Koldyk, D.R. (2004). The Shequ experiment: Grassroots political reform in urban China. Journal of Contemporary China, 13(41), 747-777.

Fan, C.C. (2001). The elite, the native, and the outsiders: Migration and labor market segmentation in urban China. Annals of the Association of American Geographers, 92(1), 103-124.

Henn, M., Weinstein, M., \& Forrest, S. (2005). Uninterested youth? Young people's attitudes towards party politics in Britain. Political Studies, 53(3), 556-578.

Huo, X. (2007). Rural migrant workers' civilization and political participation. Exploration, 109, $41-46$.

Kao, G., \& Rutherford, L.T. (2007). Does social capital still matter? Immigrant minority disadvantage in school-specific social capital and its effects on academic achievement. Sociological Perspectives, 50(1), 27-52.

Krishna, A. (2002). Enhancing political participation in democracies: What is the role of social capital? Comparative Political Studies, 35(4), 437-460.

Lee, C.K. (1998). Gender and the South China miracle: Two worlds of factory women. Berkeley: University of California Press.

Li, H., \& Zahniser, St. (2002). The determinants of temporary rural-to-urban migration in China. Urban Studies, 39, 2219-2235.

Li, X., Stanton, B., Chen, X., Hong, Y., Fang, X., Lin, D., et al. (2006). Health indicators and geographic mobility among young rural-to-urban migrants in China. World Health Population, 8(2), 5-21.

Lindström, M. (2005). Ethnic differences in social participation and social capital in Malmö, Sweden: A population-based study. Social Science and Medicine, 60(7), 1527-1546.

Liu, Y., \& Liu, W. (2008). From civil participation to mass participation. Zhejiang Social Sciences, 2008(1), 86-92.

Mitchell, A.D., \& Bossert, T.J. (2007). Measuring dimensions of social capital: Evidence from surveys in poor communities in Nicaragua. Social Science \& Medicine, 64(1), 50-63.

Nakhaie, M.R. (2008). Social capital and political participation of Canadians. Canadian Journal of Political Science, 41(4), 835-860.

National Bureau of Statistics of China. (2009, March 25). Rural migrant workers amounted to 225.42 million nationwide at the end of 2008. Beijing: National Bureau of Statistics of China. Retrieved January 10, 2010, from http://www.stats.gov.cn/tjfx/fxbg/t20090325_ 402547406.htm

Palloni, A., Massey, D.S., Ceballos, M., Espinosa, K., \& Spittel, M. (2001). Social capital and international migration: A test using information on family networks. American Journal of Sociology, 106(5), 1262-1298.

Perkins, D.D., Brown, B.B., \& Taylor, R.B. (1996). The ecology of empowerment: Predicting participation in community organizations. Journal of Social Issues, 52(1), 85-110.

Perkins, D.D., Hughey, J., \& Speer, P.W. (2002). Community psychology perspectives on social capital theory and community development practice. Journal of the Community Development Society, 33(1), 33-52.

Prezza, M., Amici, M., Roberti, T., \& Tedeschi, G. (2001). Sense of community referred to the whole town: Its relations with neighboring, loneliness, life satisfaction, and area of residence. Journal of Community Psychology, 29(1), 29-52.

Putnam, R.D. (1993). Making democracy work: Civic traditions in modern Italy. Princeton, NJ: Princeton University Press.

Ruf, G.A. (1998). Cadres and kin: Making a socialist village in West China, 1921-1991. Stanford, CA: Stanford University Press.

Schlozman, S., Verba, K.L., \& Brady, H. (1995). Participation's not a paradox: The view from American activists. British Journal of Political Science, 25, 1-36. 
Schmitt, N. (1996). Uses and abuses of coefficient alpha. Psychological Assessment, 8, 350-353.

Seidman, E., Allen, L., Aber, J.L., \& Mitchell, C. (1995). Development and validation of adolescent-perceived microsystem scales: Social support, daily hassles, and involvement. American Journal of Community Psychology, 23(3), 355-388.

Togeby, L. (2004). It depends... How organizational participation affects political participation and social trust among second-generation immigrants in Denmark. Journal of Ethnic and Migration Studies, 30(3), 509-529.

Wang, H., Schlesinger, M., Wang, H., \& Hsiao, W.C. (2009). The flip-side of social capital: The distinctive influences of trust and mistrust on health in rural China. Social Science \& Medicine, 68(1), 133-142.

Wu, X., \& Ye, S. (2008). Rural migrant workers' political participation during social harmony construction. Journal of Chongqing Institute of Technology (Social Science), 22(6), 101-103.

Xinhua News (October 16, 2007). Chongqing to observe China's first Rural Migrant Worker's Day. Xinhua News Agency, retrieved in February 1, 2009, from http://www.china.org.cn/ china/local/2007-10/16/content_1228312.htm

$\mathrm{Xu}$, Q. (2007). Community participation in urban China: Identifying mobilization factors. Nonprofit and Voluntary Sector Quarterly, 36(4), 622-642.

Xu, Q., \& Chow, J.C-C. (2006) Urban community in China: Service, participation, and development. International Journal of Social Welfare, 15, 199-208.

Xu, Q., Gao, J., \& Yan, M.C. (2005). Community centers in urban China: Context, development, and limitations. Journal of Community Practice, 13(3), 73-90.

Xu, Q., Guan, X., \& Yao, F. (in press). Welfare program participation among rural-to-urban migrant workers in China. International Journal of Social Welfare.

Xu, Q., Perkins, D.D., \& Chow, J.C-C. (2010). Sense of community, neighboring, and social capital as predictors of local political participation in China. American Journal of Community Psychology, 45(3-4), 259-271.

Yang, D.T. (1999). Urban-biased policies and rising income inequality in China. The American Economic Review, 89(2), 306-310.

Yang, Y., \& Zhu, C. (2007). Citizen participation and urban migrant workers. Social Crossing, 2007(6), 79-83.

Yip, W., Subramanian, S.V., Mitchell, A.D., Lee, D.T.S., Wang, J., \& Kawachi, I. (2007). Does social capital enhance health and well-being? Evidence from rural China. Social Science \& Medicine, 64(1), 35-49.

Zhao, B. (2008). New generation migrant workers' participation in volunteer services. Youth Studies, 2008(5), 23-26.

Zhou, M. (2008). The ethnic system of supplementary education: Non-profit and for-profit institutions in Los Angeles' Chinese immigrant community. In M. Shinn \& H. Yoshikawa (Eds.), Toward positive youth development: Transforming schools and community programs (pp. 229-251). New York: Oxford University Press.

Ziersch, A.M., Baum, F.E., MacDougall, C., \& Putland, C. (2005). Neighbourhood life and social capital: The implications for health. Social Science \& Medicine, 60(1), 71-86. 